\title{
Microstructure and mechanical properties of surface treated cast titanium with Nd:YAG laser
}

Angéline Poulon-Quintin ${ }^{\mathrm{a}}$, Etsuko Watanabe ${ }^{\mathrm{b}}$, Caroline Bertrand ${ }^{\mathrm{a}}$, Ikuya Watanabe* ${ }^{\mathrm{b}}$

${ }^{a}$ CNRS, Université de Bordeaux, ICMCB, Pessac, France

${ }^{\mathrm{b}}$ Department of Dental and Biomedical Materials Science, Nagasaki University Graduate School of Biomedical Science, Nagasaki, Japan

*Corresponding author:

Dr. Ikuya Watanabe

Department of Dental and Biomedical Materials Science

Nagasaki University Graduate School of Biomedical Science

1-7-1 Sakamoto Nagasaki 852-8588, Japan

Tel/ Fax +81-95-819-7656

Email: ikuyaw@nagasaki-u.ac.jp

Key words:

Titanium

Laser

Surface

Microstructure

Strength

Hardness 


\section{Abstract}

Objective: To investigate the effect of laser surface treatment of cast titanium alloy on microstructure and mechanical properties.

Methods: Dumbbell- and plate-shaped cast titanium specimens were prepared for mechanical testing and microstructure analysis. After the cast surfaces of each specimen were laser-treated using a dental Nd:YAG laser machine at $240 \mathrm{~V}$ and $300 \mathrm{~V}$ with and without argon gas shielding, tensile testing and microstructure analysis were conducted. Hardness depth profiles were also made from the cross-section of laser-treated cast specimens. Microstructural and chemical analysis were performed by means of the SEM, XRD, AES and WDS.

Results: The results of tensile testing and Vickers hardness depth profiling showed that laser treatment improved the mechanical properties. Bulk microstructure of as-cast titanium was mainly composed of $\alpha$-grains with acicular and widmanstatten patterns. The laser melted zone was characterized by columnar beta grains. When the emission voltage of laser increased to $300 \mathrm{~V}$, a larger grain size was promoted. The XRD analysis indicated that the beta phase formation was clearly noticeable after laser surface treatment. Supplementary marked peaks of the $\mathrm{TiO}, \mathrm{TiO}_{2}$ and $\mathrm{Ti}_{2} \mathrm{~N}$ were detected without argon gas shielding. When argon shielding gas was used, the presence of titanium oxide was significantly reduced and the peaks of titanium nitride disappeared.

Significance: Laser treatment on cast titanium surfaces showed significant enhancement of mechanical properties and modification of microstructures, and therefore could produce reliable titanium metal frameworks for dental prostheses. 


\section{Introduction}

Titanium and titanium alloys have been widely used for aerospace technology and surgical implants because of their high corrosion resistance, excellent biocompatibility, good oxidation resistance, strength-weight ratio and low mass-to-volume ratio. However, the commercially pure titanium (CP-Ti) possesses low mechanical strength, low surface hardness and poor wear resistance [1-3]. Consequently, an increased interest has been shown to modify the surface microstructure and composition with the addition of alloying elements to improve these properties.

Laser beams are widely used for surface modification [4-11] because specific thermal characteristics induced by laser irradiation can generate specific microstructures including metastable phases and nano-crystalline grains. The convective fluxes and hydrodynamic instabilities inside the irradiated surface layers contribute to the heat transport to mix the ambient gas and molten metal. Melting of surface layers for direct laser surface treatment of metallic targets should be conducted in controlled reactive atmosphere since it enhances the chemical reactions and avoids significant vaporization and particulates removal. The inclusion of light elements in titanium target occurs depending on the interactions among laser beam, substrate composition, and gaseous environment. Microstructural feature of titanium alloys, which is one of the important factors to control mechanical properties, is sensitively affected by heating temperature, holding time and cooling rate of the substrates. Laser parameters have to be optimized in order to reduce defects and to optimize microstructure [12]. Morphology of the layers created and nature of the phases formed mostly depend on the laser beam overlapping [13], the nature of surrounding gas $[4,8,10-11]$, and the intensity of laser beam $[10,14]$.

This study focused on a cast commercially pure titanium (CP-Ti) used for dental restorations. Laser treatment on cast titanium surfaces could produce reliable titanium 
metal frameworks for dental prostheses since a significant enhancement of their mechanical properties can be obtained by laser treatment [15]. The aim of this study was to investigate the effect of the Nd:YAG laser modification of the cast titanium surface on the changes of microstructure and mechanical properties.

\section{Materials and Methods}

\subsection{Specimen preparation}

Plates $(10 \mathrm{~mm} \times 10 \mathrm{~mm} \times 3 \mathrm{~mm})$ and dumbbell-shaped patterns (ISO6871, $18 \mathrm{~mm}$ for gauge length, $3 \mathrm{~mm}$ in diameter) were prepared for casting of a commercially pure titanium (CP-Ti) (grade 2, T-Alloy M. GC Corp., Tokyo, Japan). The CP-Ti was cast with a magnesia-based investment material (Selevest CB, Selec Co., Osaka, Japan) using an argon-arc melting/centrifugal titanium casting machine (Ticast Super R, Selec Co.). After casting, the molds were bench-cooled to room temperature and the cast specimens were retrieved. The surfaces of the cast specimens were air-abraded with $50 \mu \mathrm{m} \mathrm{Al}_{2} \mathrm{O}_{3}$ particles to uniform surface conditions. The specimens were then ultrasonically cleaned with acetone for $10 \mathrm{~min}$.

\subsection{Laser surface treatment}

Laser surface treatment was performed using a dental Nd:YAG laser welding machine (Neolaser L, Girrbach Dental Systems, Pforzheim, Germany) using the following parameters: spot diameter of $1.4 \mathrm{~mm}$, pulse duration of $10 \mathrm{~ms}$ and emission voltages of $240 \mathrm{~V}$ or $300 \mathrm{~V}$ [16]. During the laser treatment, argon gas shielding was applied from two nozzles set at a $45^{\circ}$ angle on both sides above the treatment area of the specimen. Laser single pulses were applied perpendicular to the long axis of each specimen in order to avoid misshaping of the straight gauge due to the induction of compressive stresses by the laser [15]. The laser-treated specimens without argon shielding were also prepared for both plate-shaped and dumbbell-shaped tensile (240 V treatment only) 
specimens. A schematic surface aspect of the overlapped laser treatment is presented in Fig. 1.

\subsection{Mechanical tests}

Tensile testing was conducted using a universal testing machine (Model 5567, Instron Corp., Canton, MA) at a crosshead speed of $1.0 \mathrm{~mm} / \mathrm{min}$. Tensile strength, modulus of elasticity and elongation were recorded. Tensile test specimens prepared were nontreated control specimens, specimens laser-treated at $240 \mathrm{~V}$ with and without argon gas shielding and specimens treated at $300 \mathrm{~V}$ with argon gas shielding. The data were statistically analyzed by ANOVA and Tukey's post-hoc test at a significant level set at $\alpha=0.05$.

\subsection{Hardness measurements}

Hardness depth-profiles were made on the cross sections of plate specimens. Vickers microhardness measurements (100g load) were performed using a microhardness tester (VMHTAUTO, Leica, Wetzlar, Germany). Measurements started at $25 \mu \mathrm{m}$ from the cast surface to $750 \mu \mathrm{m}$ in depth with $50 \mu \mathrm{m}$ increments. Five measurements were averaged for each depth.

\subsection{Material characterization}

To determine the compounds formed during surface treatments, X-ray diffraction (XRD) was carried out on a $\theta / 2 \theta$ reflection geometry using $\mathrm{CuK}_{\alpha}$ radiation (PW1820, Philips, Eindhoven, Netherlands). The $\mathrm{Cu} \mathrm{X}$-ray tube voltage was set to $40 \mathrm{kV}$, tube current to $40 \mathrm{~mA}$, a two-theta scanning rate of $0.02^{\circ} / \mathrm{min}$ and an analysis region size of $0.5 \mathrm{~cm}^{2}$. SEM morphology observations (JMS 6360A, JEOL, Tokyo, Japan) were performed on the cross-sections of treated plate specimens. Wavelength-energy dispersive x-ray spectrometric (WDS) analysis was used for quantitative element analysis (EPMA SX100, Cameca, Mahwah, NJ). Auger Electron Spectroscopy (AES) 
profiling was carried out under the argon ion beam etching ( $4 \mathrm{kV}$ and $0.5 \mathrm{~mA}$ ) using a scanning auger system (MICROLAB 310F, VG Scientific, East Grinstead, UK). The spot surface area was $3 \mu \mathrm{m}^{2}$ and the theoretical etching rate was $0.2 \mathrm{~nm} \mathrm{~s}^{-1}$.

\section{Results}

\subsection{Tensile properties}

The results of tensile testing are summarized in Table 1 . The highest tensile strength was obtained for the specimens laser-treated at $300 \mathrm{~V}$ with argon shielding (significant, $\mathrm{p}<0.05$ ), followed by $240 \mathrm{~V}$ with argon shielding, $240 \mathrm{~V}$ without argon shielding, and as-cast CP-Ti. The specimens laser-treated at $300 \mathrm{~V}$ with argon shielding also showed the significantly highest elongation value among the groups. There was no statistical difference in tensile strength, elongation and elastic modulus between as-cast CP-Ti specimens and specimens laser-treated at $240 \mathrm{~V}$ without argon. The laser treated specimens with argon shielding showed the higher values of elastic modulus than the as-cast specimen.

\subsection{Hardness depth profiles}

Microhardness depth profiles obtained from the plate specimens are shown in Fig. 1. The hardness of the laser treated groups gradually decreased from the top surface down to $200 \mu \mathrm{m}$ and reached to bulk hardness. Regardless of voltage, the hardness values of specimens treated with argon shielding were lower than those without shielding. Bulk hardness values of all treated groups were similar to that of the as-cast control specimens (deeper than $250 \mu \mathrm{m}$ ).

\subsection{Microstructure analysis of the surfaces}

XRD analysis

Fig. 2 shows XRD patterns from as-cast CP-Ti surface, laser-treated surfaces at $300 \mathrm{~V}$ with and without argon shielding. Regardless of the voltage, spectra were similar in the 
fixed gas condition. The as-cast CP-Ti was mainly composed of alpha-phase even though the peak $\left(38.3^{\circ}\right)$ widening revealed the presence of beta phase. After laser surface treatment, beta phase formation was clearly noticeable. The supplementary marked peaks of titanium oxide (TiO JCPDS-12-0754 and $\mathrm{TiO}_{2} \mathrm{JCPDS}^{-21-1272)}$ and titanium nitride $\left(\mathrm{Ti}_{2} \mathrm{~N}\right.$ JCPDS-23-1455) were noticed when argon shielding gas was not used. Under the argon gas shielding, the presence of titanium oxide was significantly reduced, and the peaks of titanium nitride disappeared.

Microstructure analysis

The SEM cross-sectional macrographs of laser treated CP-Ti are shown in Fig. 3. Three zones were observed: laser-melted zone (LMZ), heat-affected zone (HAZ) and raw material (RM). The average depth values (based on five measurements) of laser-melted zone (LMZ) were summarized in Table 2. The deeper spot depths were obtained for the higher voltage and when the argon shielding gas was used. The RM microstructure of as-cast CP-Ti ( $\alpha$-alloy) was mainly composed of $\alpha$-grains with different morphologies (acicular and widmanstatten patterns). The LMZ was characterized by columnar beta grains. When the emission voltage increased to $300 \mathrm{~V}$, a larger grain size was promoted. In the far HAZ region from LMZ, microstructures were composed of primary alphaphase dispersed in a matrix of transformed beta.

AES analysis of top surface

The AES depth profiles ( $\mathrm{Ti}$ and $\mathrm{O}$ ) obtained from the top surface to $150 \mu \mathrm{m}$ in depth are presented in Fig.4. Without argon shielding, the concentration of oxygen was approximately 40 at.\% at the top surface, then stabilized at 30 at.\% until $12 \mu \mathrm{m}$ in depth, thereafter increased up to 35 at.\% for higher depth values (60 - $140 \mu \mathrm{m})$. Whereas, when argon shielding was used, the oxygen content started from 33 at.\% and dropped 
down to 20 at.\% within $1 \mu \mathrm{m}$ in depth and then it stabilized around 15 at.\% in average until $2 \mu \mathrm{m}$ and again increased up to 20 at.\%.

\section{Discussion}

In cast titanium prostheses, hard and brittle cast surfaces are generated by the reaction between molten titanium and investment material during casting due to their high chemical reactivity (inclusion of impurities such as oxygen, nitrogen and carbon occurs) [18] compared to machined titanium for CAD/CAM restoration. The laser surface treatment applied in this study modified surface microstructure and enhanced the mechanical strength, particularly for the tensile strength of the specimens laser-treated at $300 \mathrm{~V}$.

The grain size and the morphology of the laser-melted zone (LMZ) are affected by the heat flow during weld-solidification. Therefore, the columnar beta grains in the LMZ were created inward from the raw material in a direction according to the maximum temperature gradient. Appreciable beta grain growth occurred in the near-HAZ directly adjacent to the weld fusion line where the peak of temperature changes from the alloy solidus down to the beta transus. In the near-HAZ regions, high cooling rates associated with low-energy input promoted transformation of beta to alpha'-martensite phase identified by grains morphology changes combined with XRD results. The AES depth profiles (300V) indicated the presence of a top layer with higher oxygen content (Fig. 4). Its thickness was approximately $1 \mu \mathrm{m}$ with argon shielding and $5 \mu \mathrm{m}$ without argon. A film of titanium oxide ( $\mathrm{TiO}$ or $\mathrm{TiO}_{2}$ ) on the top surface (Fig. 2) and a layer of fine martensite (Fig. 3) were produced on the surface by quick laser re-melting processes (melt-pool-solidification). The alpha case is a "thin, hard, brittle surface layer" that is created as the liquid titanium interacts with oxygen. At the temperatures greater than $600{ }^{\circ} \mathrm{C}$, the reaction kinetics allows approximately $33 \%$ of the atmospheric oxygen to 
dissolve in the exposed liquid titanium surface. Correlation between XRD results, AES analysis and morphological changes of the top surface microstructure validates the presence of oxide phases and surface alpha case layer. Previous reports $[9,13,17]$ studied on laser melting of pure $\mathrm{Ti}$ and $\mathrm{Ti}-6 \mathrm{Al}-4 \mathrm{~V}$ alloy found that different titanium oxides were formed in the surface layers of the samples. They also showed that the remelting significantly improved the corrosion and wear resistances. In this study, when the surface was laser-treated without argon, significant peaks corresponding to $\mathrm{TiO}_{2}$ were noticeable on XRD spectrum $\left(28.3\right.$ and $\left.42^{\circ}\right)$, whereas these peaks disappeared or were too small to be detected and only TiO was present when the surface was treated with argon. Lavisse et. al. [14] reported an amount increase of the nitrogen and oxygen in the layer in accordance with the significant increase of laser fluence. Such behavior was not clearly noticed when the $240 \mathrm{~V}$ and $300 \mathrm{~V}$ samples were compared. This may be because of the microstructure inhomogeneity of the molten material. For all samples, XRD peak positions were slightly moved from their standard position. This is probably due to high residual stress developed by the quick melting and solidification during laser process. Moreover, the presence of characteristic peaks of $\mathrm{TiO}_{2}$ indicated that the fluence values used in this study were high enough to promote the formation of the highly oxidized phases without argon gas shielding. This result was in agreement with previous studies $[7,13]$ which reported that this phase was only obtained with fluence higher than $280 \mathrm{~J} / \mathrm{cm}^{2}$ under normal environmental atmosphere (corresponding fluence values vary from 340 up to $430 \mathrm{~J} / \mathrm{cm}^{2}$ for $240 \mathrm{~V}$ - $300 \mathrm{~V}$ in this study). Regardless of the fluence value, the oxidation degree was reduced under the argon shielding due to the low oxygen content on the top surface. The presence of the TiN phase without argon shielding was due to the diffusion of nitrogen in the ambient air during laser irradiation since the melted surface vaporized and created plasma state on its surface. 
The growth of symmetric $\alpha$-Ti during heat propagation and quick cooling similar to a quenching process led to the formation and stabilization of $\beta$-Ti. The structure of $\beta$-Ti was similar to the TiO cubic structure. Oxygen atoms diffused into the melted $\beta$-Ti to form TiO with a larger lattice due to the incorporation of oxygen. This mechanism explained the presence of $\mathrm{TiO}$ with the lack of significant peak of $\beta$-Ti under argon shielding, and the formation of $\mathrm{Ti}_{2} \mathrm{~N}$ and $\mathrm{TiO}_{2}$ with the presence of $\beta$-Ti without argon shielding. Even with a well-controlled flow of inert argon gas, when titanium was melted by the high energy laser, the $\alpha$-Ti may expand to let non-excluded oxygen and nitrogen enter into the interstitial space in quantities depending on the fluence. On the top of the oxygen-rich area, the presence of TiO film on the surface treated by Nd:YAG laser under the ambient air was also confirmed by Langlade et. al.[9].

Since the voltage controls the welding energy, an increase of voltage leads to a greater welding depth $[4-15,17]$. Chai and Chou [18] reported that pulse duration is not a significant factor to affect the Ultimate Tensile Strength (UTS) or the Yield Strength (YS). They concluded that the mechanical properties were influenced by the minor interstitial dissolved elements such as oxygen, nitrogen and carbon, and that if too many impurities enter into the titanium, the mechanical properties become brittle. In this study, impurity content and hardness values in a fixed voltage were always higher without argon gas shielding. Depending on the process conditions, the depth of individual spot varies from $150 \mu \mathrm{m}$ to $415 \mu \mathrm{m}$ (Table 2), whereas RM hardness value reached to the ascast bulk hardness beyond $200 \mu \mathrm{m}$ in depth (Figure 1). The volume ratio of $\beta$-Ti depends on the oxygen content as well as the transus temperature [20] and the hardening by oxygen follows a parabolic dependence on concentration. There is negligible hardening associated with the production of $\alpha^{\prime}$ martensite when the grain size is large 
and when no supersaturation of substitutional solute atoms occurs. When samples are laser-treated under argon shielding, the increase of tensile strength can be explained by the oxygen diffusion. In general, the increase of tensile strength reduces the elongation of tensile specimens. The changes of elongation and Young modulus for $240 \mathrm{~V}$ correspond to the changes of phase and microstructure. On the other hand, the elongation for $300 \mathrm{~V}$ significantly increased, and Young modulus is slightly reduced compared to 240V. For both conditions, laser affected the hardness till $200 \mu \mathrm{m}$ in depth. However, the average depth values of laser-melted zone (LMZ) reached to $207 \mu \mathrm{m}$ for $240 \mathrm{~V}$ and to $415 \mu \mathrm{m}$ for $300 \mathrm{~V}$, respectively. Furthermore, the WDS analysis demonstrated that oxygen diffusion occurred even below the weld fusion line [the bottom of a spot (LMZ)] as observed in Fig. 5. The appreciable grain growth occurred in the near-HAZ directly adjacent to the weld fusion line is certainly in part of the reasons for the increase of elongation for $300 \mathrm{~V}$. As for as the $240 \mathrm{~V}$, the limit of LMZ (200 $\mu \mathrm{m}$ ) corresponds to the end of the hardness affected zone. This result could also explain the slight reduction of Young modulus for $300 \mathrm{~V}$. The specific microstructure of the LMZ (change of grain size, morphology of grains and phases) due to rapid solidification mechanism and the variation of impurity contents validate the change of mechanical properties.

To determine the longitudinal young modulus, the gauge zone of laser-treated specimen is considered as a cylinder (diameter $\mathrm{d}=3.12 \mathrm{~mm}$ ) which is composed of inner cylinder and outer hard coating (thickness e) as shown in Fig. 6. As the inner bulk CP$\mathrm{Ti}$ and outer surface treated area are assumed to have similar elongation, the young modulus $\mathrm{E}$ of the specimen can be estimated using a composite longitudinal young modulus calculation:

$\mathrm{E}=\mathrm{V}_{\mathrm{LST}} \times \mathrm{E}_{\mathrm{LST}}+\mathrm{V}_{\mathrm{CP}-\mathrm{Ti}} \times \mathrm{E}_{\mathrm{CP}-\mathrm{Ti}}$ 
Where $\mathrm{E}_{\mathrm{LST}}$ and $\mathrm{E}_{\mathrm{CP}-\mathrm{Ti}}$ are Young moduli of the laser surface treated (LST) material and the CP-Ti respectively, where $\mathrm{V}$ is the volume ratio $\left(\mathrm{V}_{\mathrm{LST}}=(\mathrm{d}-2 \mathrm{e}) / \mathrm{d} ; \mathrm{V}_{\mathrm{CP}-\mathrm{Ti}}=1-\mathrm{V}_{\mathrm{LST}}\right.$; $\mathrm{d}=3.12 \mathrm{~mm}$ ). Using the depth values (Table2) for the laser surface treated area under argon shielding, calculated Young moduli of the laser surface treated area $\left(\mathrm{E}_{\mathrm{LST}}\right)$ for 240 V and $300 \mathrm{~V}$ are $168 \pm 120 \mathrm{GPa}$ and $150 \pm 91 \mathrm{GPa}$, respectively.

As expected, the values obtained are higher than the young modulus of un-treated CP-Ti (109 \pm 19 GPa, Table 1). High Young modulus of the surface treated area corresponds to the formation of titanium oxides, $\beta$ and $\alpha$ '-phases, because the $\beta$ phase has a lower $\mathrm{E}$ value than alpha titanium phases. Moreover, a compound with both the alpha and beta phases creates a titanium compound with greater ductility, strength, and high temperature strength than pure alpha titanium [21]. Whereas the presence of oxide reduces ductility and increases strength even if it does not affect the properties of the interior CP-Ti.

\section{Conclusion}

Emission voltage for laser impacted on spot depth, grain morphology, microstructure and mechanical properties. Microstructural observations indicated that the laser fluence was a key parameter to control microstructure and to improve the mechanical properties. The impurities inclusion/diffusion of light elements such as oxygen and nitrogen during laser processing was responsible for surface hardening (inside the spots) and mechanical strengthening, whereas the grain size distribution and the phases were in charge of the increase of plasticity (elongation value increased).

\section{Acknowledgments}

The author would like to thank Dr. Michel Lahaye (CeCaMa, Université de Bordeaux1) for AES and WDS characterization. 
[1] Properties and Selection: Stainless steels, tool materials and special purpose metals. Metals Handbook, Metals Park, OH, Vol.3, ASM, $9^{\text {th }}$ edn., 1980;353-417.

[2] Williams DF. Titanium and titanium alloys. In: Williams DF, editor. Biocompatibility of clinical implant materials. Boca Raton, CRC Press, 1984: 44-7.

[3] Peters M., Hemptenmacher J., Kumpfert J. and Leyens C. Titanium and Titanium Alloys: Fundamentals and Applications. Editors Christoph Leyens, Manfred Peters, ISBN: 9783527602117, 2005;1-36.

[4] Mahmood K, Farid N, Ghauri M, Afzal N, Idrees Y, Mubarik F. Effects of laser irradiation on the mechanical response of polycrystalline titanium. Physica Scripta 2010;82:045606 (6pp).

[5] Richter E, Piekoszewski J, Wieser E, Prokert F, Stanislawski J, Walis L, Reuther H. Modification of titanium surface by its alloying with silicon using intense pulsed plasma beams. Surf Coat Technol 2002;158-9: 324-7.

[6] Luo G, Wu G, Huang Z, Ruan Z. Microstructure transformations of laser-surfacemelted near-alpha titanium alloy. Mater Charact 2009;60:525-9.

[7] Braga F, Marques R, Filho E, Guastaldi A. Surface modification of Ti dental implants by Nd:YVO 4 laser irradiation. Appl Surf Sci 2007;253:9203-8.

[8] Tian Y, Chen C, Li S, Huo Q. Research progress on laser surface modification of titanium alloys. Appl Surf Sci 2005;242:177-84.

[9] Langlade C, Vannes A, Krafft J, Martin J. Surface modification and tribological behaviour of titanium and titanium alloys after YAG-laser treatments. Surf Coat Technol 1998; 100-101:383-7.

[10] Lavisse L, Jouvard J, Gallien J, Berger P, Grevey D, Naudy Ph. The influence of laser power and repetition rate on oxygen and nitrogen insertion into titanium using pulsed Nd:YAG laser irradiation. Appl Surf Sci 2007;254 :916-20.

[11] Gyorgy1 E, Perez del Pino A, Serra P, Morenza J. Influence of the ambient gas in laser structuring of the titanium surface. Surf Coat Techno 2004;187:245-9.

[12] Bertrand C, Poulon-Quintin A. Proposals for laser welding optimization in prosthetic dentistry. J Prosthodont 2010;19:69-76.

[13] Pérez del Pino A, Serra P, Morenza J. Laser surface processing of titanium in air: Influence of scan traces overlapping. J Laser Appl 2003;15:120-3.

[14] Lavisse L, Sahour M, Jouvard J, Pillon G, Marco de Lucas M, Bourgeois S, Grevey D. Growth of titanium oxynitride layers by short pulsed Nd:YAG laser treatment of Ti plates: Influence of the cumulated laser fluence. Appl Surf Sci 2009;255:5515-8.

[15] Watanabe I, McBride M, Newton P, Kurtz K. Laser surface treatment to improve mechanical properties of cast titanium. Dent Mater 2009; 25:629-33. 
[16] Baba N., Watanabe I. Penetration depth into dental casting alloys by Nd:YAG laser. J Biomed Mater Res 2005;72B:64-8.

[17] Tian S, Chen Z, Li T, Huo H. Research progress on laser surface modification of titanium alloys. Appl Surf Sci 2005;242:177-184.

[18] Chai T, Chou K. Mechanical properties of laser-welded cast titanium joints under different conditions. J Prosthetic Dent 1998;79:477-83.

[19] Ibrahim M, Mhaede M, Wagner L. Effect of annealing temperature on microstructure and mechanical properties of hot swaged CP-Ti produced by investment casting. J Mat Eng Perform 2010;doi:10.10007/s11665-010-9799-6.

[20] Kahveci I, Welsch E. Effect of oxygen on the hardness and alpha/beta phase ratio of Ti-6Al-4V. Scripta Metall 1986;20:1287-1290.

[21] Moiseyev N. Titanium alloys: Russian aircraft and aerospace applications.

Advances in metallic alloys. CRC Press 2005, ISBN: 9780849332739. 
Table 1 - Results of tensile testing for as-cast CP-Ti specimens.

\begin{tabular}{cccc}
\hline & Tensile strength (MPa) & Elongation (\%) & Elastic Modulus (GPa) \\
\hline CP-Ti & $437(94)$ & $9(5)$ & $109(19)$ \\
$240 \mathrm{~V}$ with Ar & $561(51)$ & $8(3)$ & $160(35)$ \\
$300 \mathrm{~V}$ with Ar & $789(17)$ & $19(5)$ & $139(38)$ \\
$240 \mathrm{~V}$ without Ar & $457(43)$ & $5(3)$ & $114(6)$ \\
\hline
\end{tabular}

Table 2 - Average depth values ( $\mu \mathrm{m})$ of laser-melted zone (LMZ).

\begin{tabular}{ccc}
\hline Ar shielding & $240 \mathrm{~V}$ & $300 \mathrm{~V}$ \\
\hline Without Ar & $150 \pm 50$ & $225 \pm 75$ \\
With Ar & $207 \pm 75$ & $415 \pm 60$ \\
\hline
\end{tabular}


Figure legends

Fig. 1 - Comparison of hardness depth profiles at $25 \mu \mathrm{m}$ from the cast surface to 750 $\mu \mathrm{m}$ in depth. Average value obtained for each depth (each dot on a dotted line) from the cast surface (red line) on the right upper corner.

Fig. 2 - XRD spectra of the as-cast CP-Ti plate surface, the plate surfaces laser-treated at $300 \mathrm{~V}$ with and without argon.

Fig. 3 - BSE-SEM images of the microstructure close to the top surface.

Fig. 4 - AES results of the $\mathrm{Ti}$ and $\mathrm{O}$ concentration close to the top surface for $300 \mathrm{~V}$ with and without argon gas shielding: a) zoom (0-20 $\mu \mathrm{m})$, b) 0-150 $\mu \mathrm{m}$.

Fig. 5 - BSE-SEM picture (left) and WDS mapping (right) of oxygen element around a spot of laser treated sample (300 V) with argon shielding.

Fig. 6 - Schematic structure of the gauge zone of a tensile test specimen (cross-section and longitudinal section). 
Fig. 1

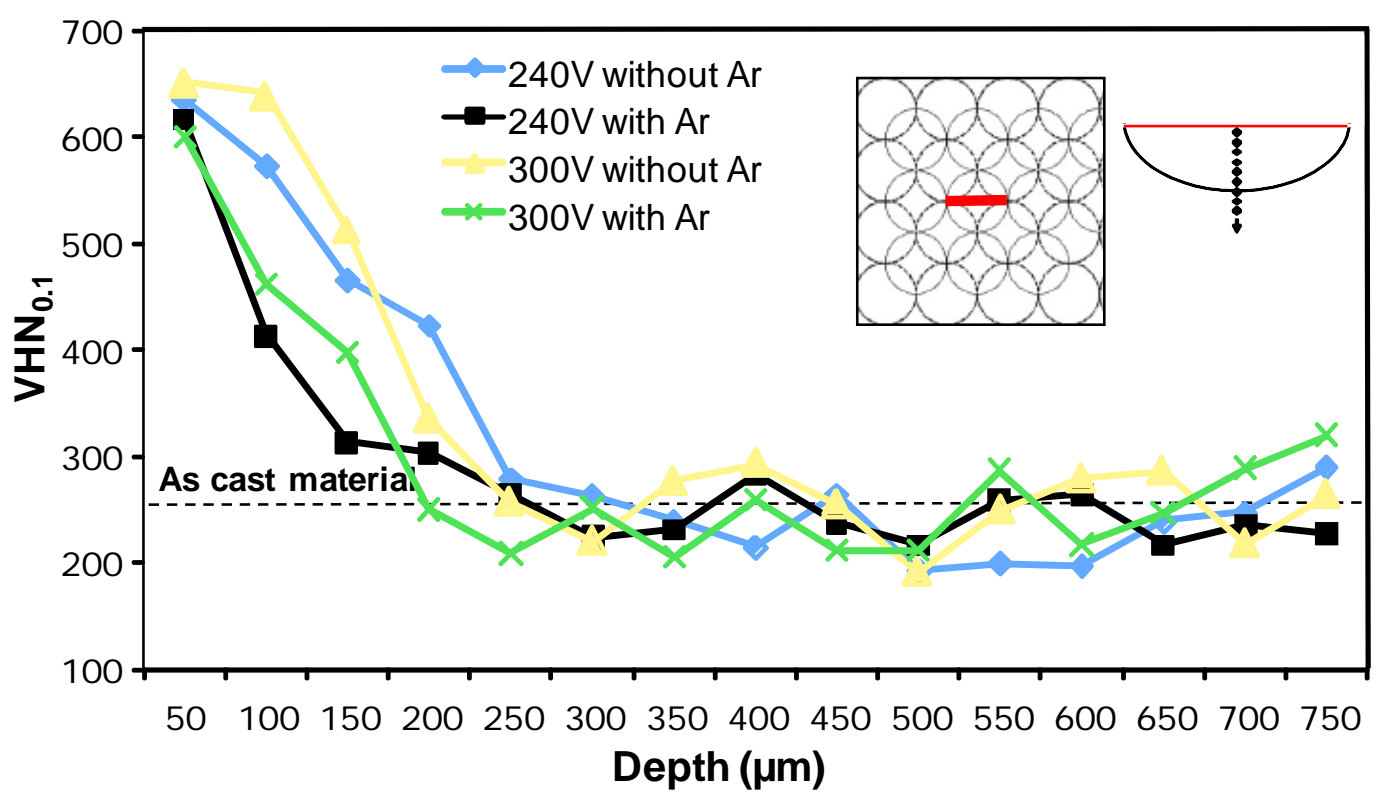


Fig. 2

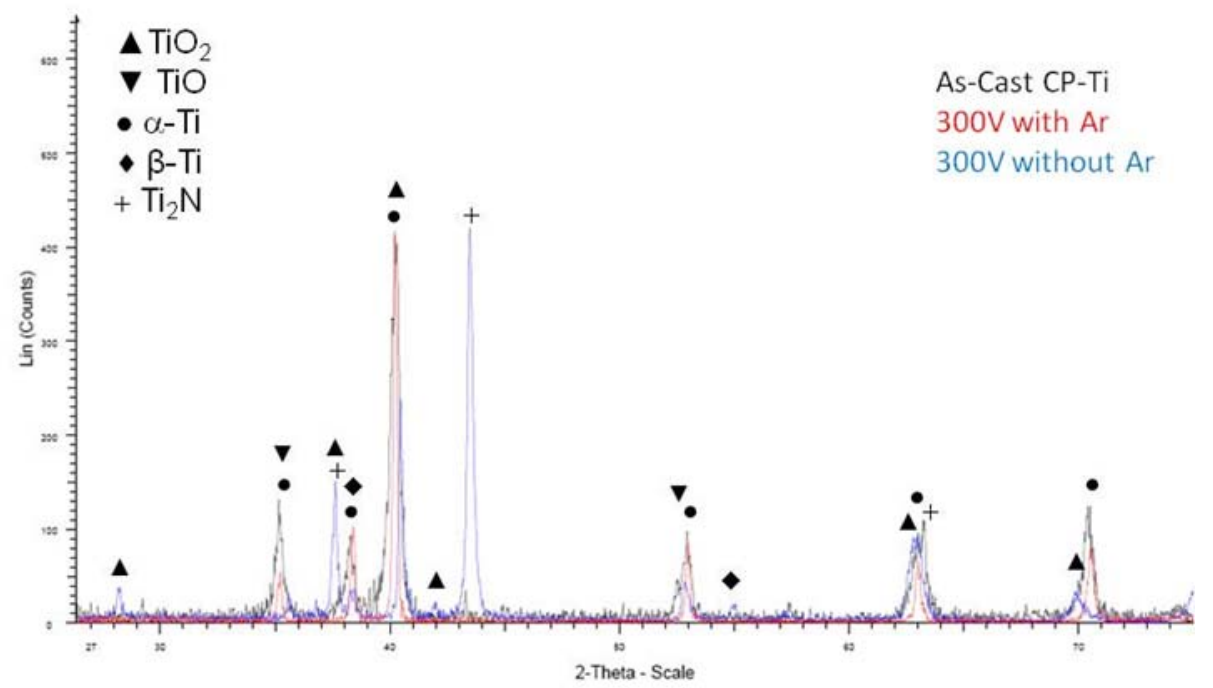


Fig. 3

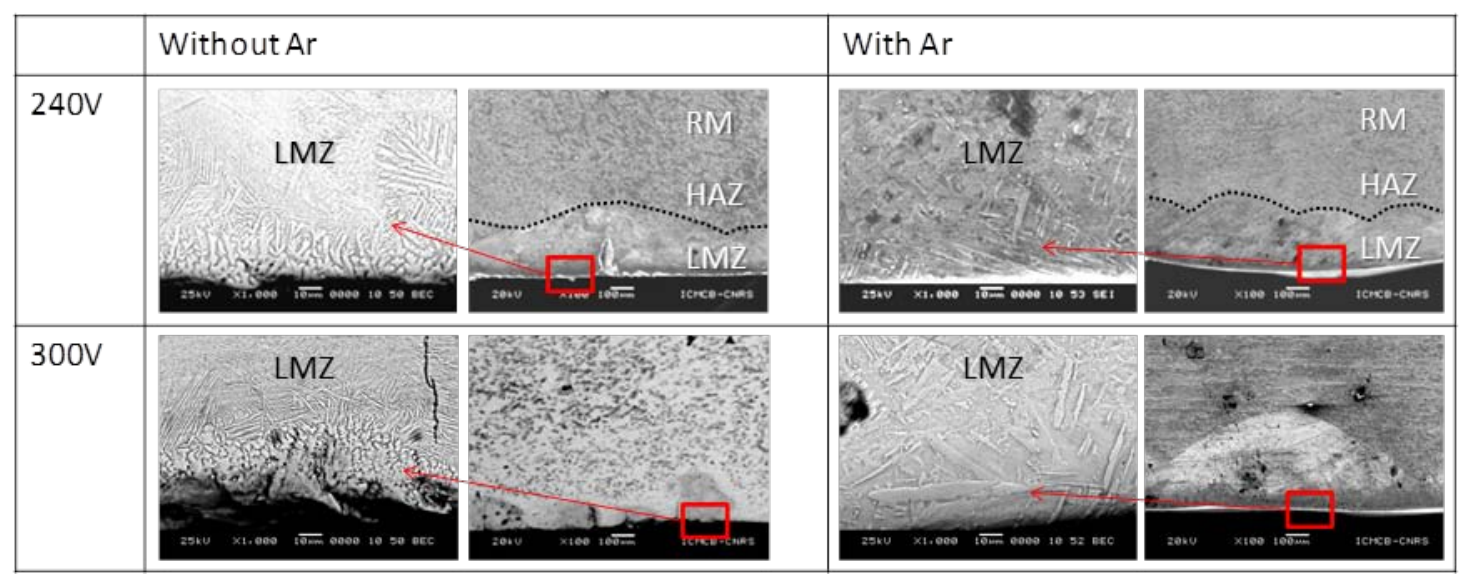


Fig. 4

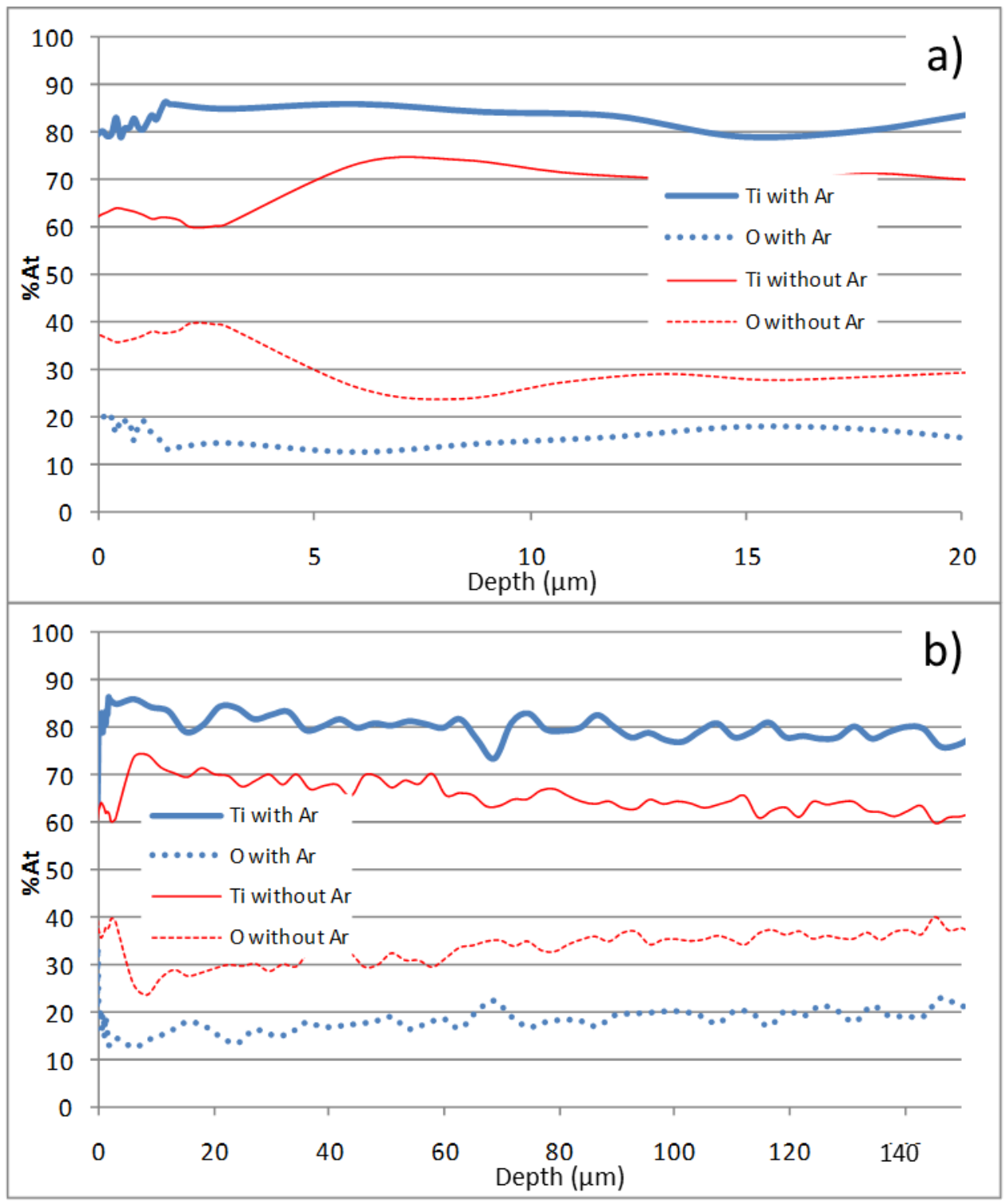


Fig. 5

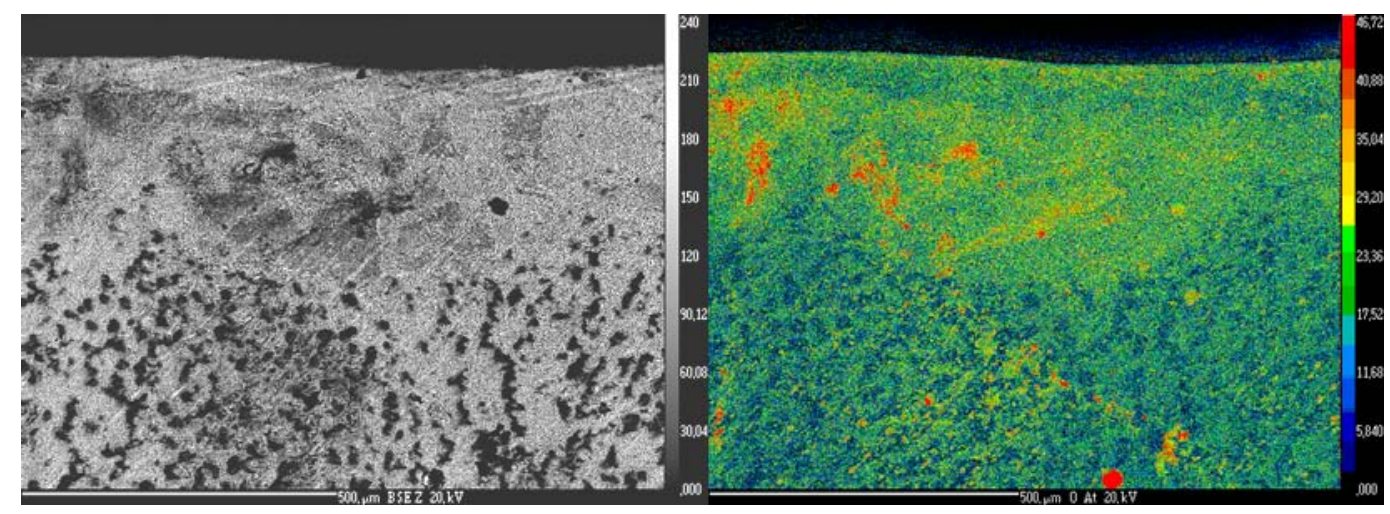


Fig. 6

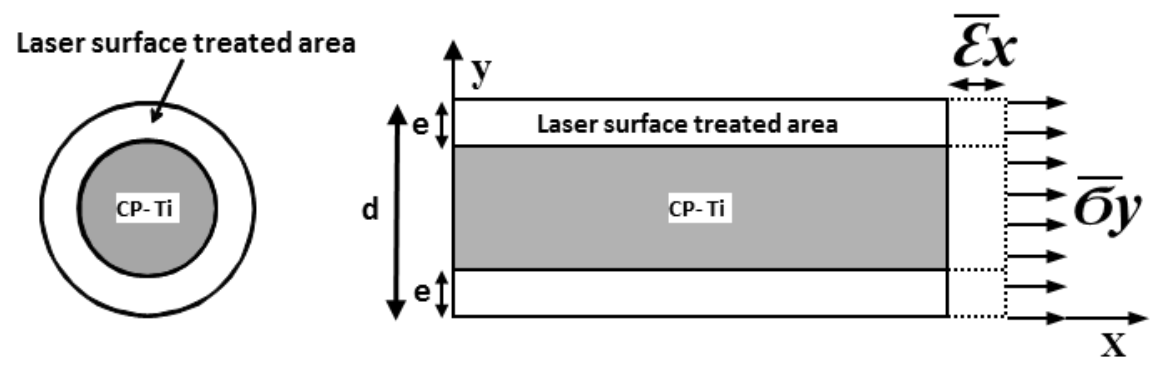

